\title{
Trends in time to diagnosis of colon cancer and impact on clinical outcomes
}

\author{
Harminder Singh MD MPH${ }^{1,2,3}$, Emma Shu $\mathrm{MSc}^{4}$, Alain Demers $\mathrm{PhD}^{2,4}$, \\ Charles $\mathrm{N}$ Bernstein $\mathrm{MD}^{1,3}$, Jane Griffith $\mathrm{PhD}^{2,4}$, Katherine Fradette $\mathrm{MSc}_{\mathrm{MPH}}{ }^{4}$
}

\begin{abstract}
H Singh, E Shu, A Demers, CN Bernstein, J Griffith, K Fradette. Trends in time to diagnosis of colon cancer and impact on clinical outcomes. Can J Gastroenterol 2012;26(12):877-880.
\end{abstract}

BACKGROUND: There has been a rapid increase in screening for colorectal cancer (CRC) over the past several years in North America. This could paradoxically lead to worsening outcomes if the system is not adapted to deal with the increased demand. For example, this could create increased wait times for endoscopy and delayed time to CRC diagnosis, which could worsen clinical outcomes such as stage at diagnosis and/or survival. No previous Canadian study has evaluated the association between time to CRC diagnosis and clinical outcomes.

METHODS: The present historical cohort study used Manitoba's population-based cancer registry and Manitoba Health administrative databases. The effect of time to diagnosis on patient survival was evaluated using Cox regression analysis with adjustment for stage at diagnosis, grade of CRC, age, sex, socioeconomic status, comorbidity index score and year of CRC diagnosis. The association between time to diagnosis and CRC stage at diagnosis was evaluated using multivariate logistic regression analysis.

RESULTS: The median time to CRC diagnosis increased significantly from 72 days ( $95 \%$ CI 61 days to 83 days) in 2004 to 105 days (95\% CI 64 days to 129 days) in the first three months of 2009 ( $P=0.04)$. There was no significant association between time to diagnosis and survival. Individuals with the longest time to diagnosis were less likely to have stage III/IV CRC at diagnosis (quartile 4 versus quartile 1: OR 0.50 [95\% CI 0.33 to 0.75$)$.

CONCLUSION: Time to CRC diagnosis is continuing to increase in Manitoba. Although the present study did not detect a significant negative clinical effect of increasing time to diagnosis, additional studies are required.

Key Words: Colon cancer; Stage at diagnosis; Survival; Time trends

\author{
Les tendances entre le délai avant de diagnostiquer \\ le cancer du côlon et les répercussions sur les \\ issues cliniques
}

HISTORIQUE : Le nombre de tests de dépistage de cancer colorectal (CCR) augmente rapidement depuis quelques années en Amérique du Nord. Paradoxalement, ce phénomène pourrait aggraver les issues si le système n'est pas adapté pour faire face à l'augmentation de la demande. Par exemple, il pourrait susciter une augmentation des temps d'attente en endoscopie et un retard du diagnostic de CCR, ce qui pourrait aggraver l'issue clinique, telle que le stade du cancer au diagnostic ou la survie. Aucune autre étude canadienne n'a évalué l'association entre le délai avant le diagnostic de CCR et les issues cliniques.

MÉTHODOLOGIE : Dans la présente étude de cohorte rétrospective, les chercheurs ont fait appel au registre du cancer en population du Manitoba et aux bases de données administratives de Santé Manitoba. Ils ont évalué l'effet du délai avant le diagnostic sur la survie des patients au moyen de l'analyse de régression de Cox, rajustée d'après le stade au diagnostic, le grade de CCR, l'âge, le sexe, la situation socioéconomique, l'indice de comorbidité et l'année du diagnostic de CCR. Ils ont évalué l'association entre le délai avant le diagnostic et le stade de CCR au diagnostic au moyen d'une analyse de régression logistique multivariée.

RÉSULTATS : Le délai médian avant le diagnostic de CCR a augmenté de manière significative, passant de 72 jours (95\% IC 61 jours à 83 jours) en 2004 à 105 jours (95\% IC 64 jours à 129 jours) pendant les trois premiers mois de $2009(\mathrm{P}=0,04)$. Il n'y avait pas d'association significative entre le délai avant le diagnostic et la survie. Ceux qui attendaient le plus longtemps avant le diagnostic étaient moins susceptibles d'être atteints d'un CCR de stade III ou IV au diagnostic (quartile 4 par rapport au quartile 1 : RRR 0,50 [95 \% IC 0,33 à 0,75). CONCLUSION : Le délai avant le diagnostic de CCR continue d'augmenter au Manitoba. Même si la présente étude n'a pas décelé d'effet clinique négatif significatif causé par le délai plus long avant le diagnostic, d'autres études s'imposent sur le sujet.

$\mathrm{W}$ ait times for cancer diagnosis and treatment are a persistent concern to the public and have received increasing attention in many countries over the past decade. In Canada, the issue of wait times for health care has generated considerable attention since the September 2004 'Deal for a Decade' meeting of the Premiers and the Prime Minister of Canada, which identified five priority service areas including cancer treatment. Most Canadian provinces, including Manitoba, have since focused on monitoring and controlling treatment delays $(1,2)$. For diagnostic delays, the focus has been on wait time for radiological tests because they are the essential modality in the diagnosis of most cancers $(1,2)$. The diagnostic work-up for colorectal cancer (CRC), however, differs from most other common cancers in that CRCs are often diagnosed using lower gastrointestinal endoscopy. CRC is the third most common cancer among Canadian men and women, and the second most common cause of cancer-related deaths (3).
There are limited data on time to diagnosis of CRC in Canada. In a recent study, we estimated that overall health system wait times or time from presentation to treatment of CRC in Manitoba increased between 2001 and 2005 (4). The largest increase occurred in the time to diagnosis. However, wait times have only received increased attention since 2005 , following the federal provincial agreement of 2004. It is, therefore, possible that the time to CRC diagnosis could have started decreasing since 2005. On the other hand, there has been a rapid increase in opportunistic CRC screening activity in Canada over the past decade (5), which could have led to further increase in diagnosis delays due to increasing demands on diagnostic services.

There are no Canadian data on the consequences of diagnostic delays for CRC on patient outcomes such as stage at diagnosis and survival.

${ }^{1}$ Internal Medicine; ${ }^{2}$ Community Health Sciences; ${ }^{3}$ IBD Clinical and Research Centre, University of Manitoba; ${ }^{4}$ CancerCare Manitoba, Department of

Epidemiology and Cancer Registry, Winnipeg, Manitoba

Correspondence: Dr Harminder Singh, Section of Gastroenterology, 805-715 McDermot Avenue, Winnipeg, Manitoba R3E 3 P4.

Telephone 204-480-1311, fax 204-789-3972, e-mail singh@cc.umanitoba.ca

Received for publication March 15, 2012. Accepted May 2, 2012 
TABLE 1

Description of patients diagnosed with colorectal adenocarcinomas included in the study

\begin{tabular}{|c|c|c|c|c|c|c|c|}
\hline & \multicolumn{7}{|c|}{ Year of diagnosis } \\
\hline & $2004(n=446)$ & $2005(n=416)$ & $2006(n=441)$ & $2007(n=448)$ & $2008(n=471)$ & $2009(n=97)$ & 2004-2009 \\
\hline Male sex & $223(50)$ & $215(52)$ & $236(54)$ & $242(54)$ & $249(54)$ & $56(58)$ & $1221(53)$ \\
\hline \multicolumn{8}{|l|}{ Colorectal cancer site } \\
\hline Colon & $287(64)$ & $277(67)$ & $299(68)$ & $289(65)$ & $311(67)$ & $62(65)$ & $1525(66)$ \\
\hline \multicolumn{8}{|l|}{ Cancer stage } \\
\hline 1 & $90(20)$ & $78(19)$ & $80(18)$ & $88(20)$ & $73(16)$ & $18(19)$ & $427(18)$ \\
\hline II & $116(26)$ & $112(27)$ & $140(32)$ & $121(27)$ & $138(30)$ & $30(31)$ & $657(28)$ \\
\hline III & $139(31)$ & $122(29)$ & $127(29)$ & $137(31)$ & $143(31)$ & $34(35)$ & $702(30)$ \\
\hline IV & $88(20)$ & $92(22)$ & $88(20)$ & $91(20)$ & $95(20)$ & $10(10)$ & $464(20)$ \\
\hline$\geq 3$ & $60(13)$ & $60(14)$ & $55(12)$ & $54(12)$ & 49 (11) & $11(11)$ & $289(13)$ \\
\hline No hospitalization & $26(6)$ & $33(8)$ & $27(6)$ & $49(11)$ & $33(7)$ & $14(15)$ & $182(8)$ \\
\hline $\begin{array}{l}\text { Admission through ER in } \\
\text { the month before CRC } \\
\text { diagnosis date }\end{array}$ & $135(30)$ & $129(31)$ & $126(29)$ & $92(21)$ & $124(27)$ & $16(17)$ & $622(27)$ \\
\hline $\begin{array}{l}\text { Deaths (up to March 31, } \\
\text { 2010) }\end{array}$ & $253(57)$ & $191(46)$ & $193(44)$ & $156(35)$ & $142(31)$ & $12(13)$ & $947(41)$ \\
\hline
\end{tabular}

Data presented as $n$ (\%) unless otherwise indicated. CRC Colorectal cancer; ER Emergency room; IQR Interquartile range; SEFI Socioeconomic Factor Index (measure of socioeconomic status)

The aim of the current study was to determine recent trends in time to diagnosis for CRC and its association with clinical outcomes.

\section{METHODS}

A historical cohort of CRC patients was built using Manitoba's population-based cancer registry (MCR) and the administrative databases maintained by Manitoba Health $(\mathrm{MH})$.

\section{Databases}

Patients diagnosed with a colorectal adenocarcinoma between January 1, 2004 and March 31, 2009 as their first cancer were identified from the MCR. The population-based MCR is maintained by CancerCare Manitoba, and receives reports on all cases of cancer in Manitoba as mandated by the Public Health Act. The coding and capture of cancer data are audited regularly by a standards setting group (the North American Association of Central Cancer Registries) and the MCR has been consistently shown to be of very high quality, including very high levels of reporting completeness and histological verification (6). The MCR contains key information on patients characteristics (age, sex, residence at diagnosis), the tumour (anatomical site, histological type and date of diagnosis), treatment (the date and general nature of surgical, radiation and systemic treatment) as well as outcome (death date, if applicable). The stage at diagnosis has routinely been recorded for all cancer cases since 2004.

$\mathrm{MH}$ is the provincial government agency responsible for provision of health care to all residents of Manitoba. MH maintains several administrative databases for the routine operation of the health care system (eg, to ensure the eligibility of health service recipients [Manitoba residents], reimburse physicians for services and monitor the use of the prescription drug plan). These data may also be used to identify key milestones in a patient's trajectory of care.

Since 1984, every resident of Manitoba has been assigned a unique personal health identification number (PHIN) by MH. Longitudinal health services use and outcomes in the province can be ascertained by deterministic linkage of health utilization files and other databases that use PHINs as a key personal identifier. The accuracy and comprehensiveness of these administrative databases have been previously established (7-9). To maintain patient confidentiality, unique identifiers were removed from all the databases and linkage of the databases were performed using encrypted PHINs.

\section{Time to CRC diagnosis}

The time to diagnosis (time between the index contact and the CRC diagnosis) was estimated using previously described methodology (4). Briefly, the process began with the diagnosis date for CRC; contacts with the health care system were worked backward in time. The first gastrointestinal investigation was determined, including abdominal radiological imaging (barium enema, computed tomography, ultrasound or plain abdominal films), lower gastrointestinal endoscopy or fecal occult blood testing (FOBT) in the year before the CRC diagnosis. The physician visit before and most likely to have generated the referral for the diagnostic investigation was considered the index contact with the health care system. The analysis was restricted to individuals with residences in Winnipeg and Brandon (the two largest municipalities in Manitoba) because some investigations, such as radiological tests and FOBT, performed at rural hospitals are not always included in the $\mathrm{MH}$ administrative databases. Approximately two-thirds of the population of Manitoba resides in Winnipeg and Brandon. The time to treatment was estimated from the date of CRC diagnosis to the date of the first definitive treatment for CRC, as recorded in the MCR.

\section{Statistical analysis}

Standard descriptive analyses were performed to describe the time to CRC diagnosis in the different years. The time trend was analyzed using the Jonckheere-Terpstra trend test.

Multivariate Cox regression analysis was performed to determine the association of time to diagnosis and survival after diagnosis. 


\begin{tabular}{|c|c|c|c|c|c|c|c|c|}
\hline & \multicolumn{6}{|c|}{ Year of diagnosis } & \multirow[b]{2}{*}{ 2004-2009 } & \multirow{2}{*}{$\begin{array}{l}\mathrm{P} \text { (time } \\
\text { trends) }\end{array}$} \\
\hline & 2004 & 2005 & 2006 & 2007 & 2008 & 2009 & & \\
\hline \multicolumn{9}{|l|}{ Time to diagnosis, days } \\
\hline Median (95\% Cl) & $72(61-83)$ & $83(69-97)$ & $78(70-92)$ & 78 (63-92) & $92(76-105)$ & $105(64-129)$ & $81(75-85)$ & 0.04 \\
\hline 90th percentile $(95 \% \mathrm{Cl})$ & $262(230-298)$ & $277(253-305)$ & $281(256-320)$ & $271(245-305)$ & $287(271-311)$ & $276(217-350)$ & $277(267-291)$ & \\
\hline \multicolumn{9}{|c|}{ Time between index contact and first colonoscopy, days } \\
\hline Median $(95 \% \mathrm{Cl})$ & $72(61-83)$ & $69(58-85)$ & $75(66-86)$ & $68(55-86)$ & $90(72-104)$ & $111(63-127)$ & $76(69-82)$ & 0.02 \\
\hline 90th percentile $(95 \% \mathrm{Cl})$ & $244(222-294)$ & $264(217-301)$ & $247(196-308)$ & $246(209-280)$ & $271(257-301)$ & $265(226-353)$ & $259(244-271)$ & \\
\hline \multicolumn{9}{|l|}{ Time to treatment, days } \\
\hline Median $(95 \% \mathrm{Cl})$ & $15(11-20)$ & $13(8-18)$ & $14(7-21)$ & $21(15-26)$ & $20(11-25)$ & $22(0-36)$ & $16(14-19)$ & 0.06 \\
\hline 75th percentile $(95 \% \mathrm{Cl})$ & $34(30-38)$ & $36(33-42)$ & $42(36-48)$ & $45(41-50)$ & $51(45-61)$ & $53(42-67)$ & $42(40-44)$ & \\
\hline 90th percentile $(95 \% \mathrm{Cl})$ & $63(54-71)$ & $62(55-73)$ & $67(60-77)$ & $76(67-85)$ & $80(72-92)$ & $82(67-113)$ & $71(67-75)$ & \\
\hline
\end{tabular}

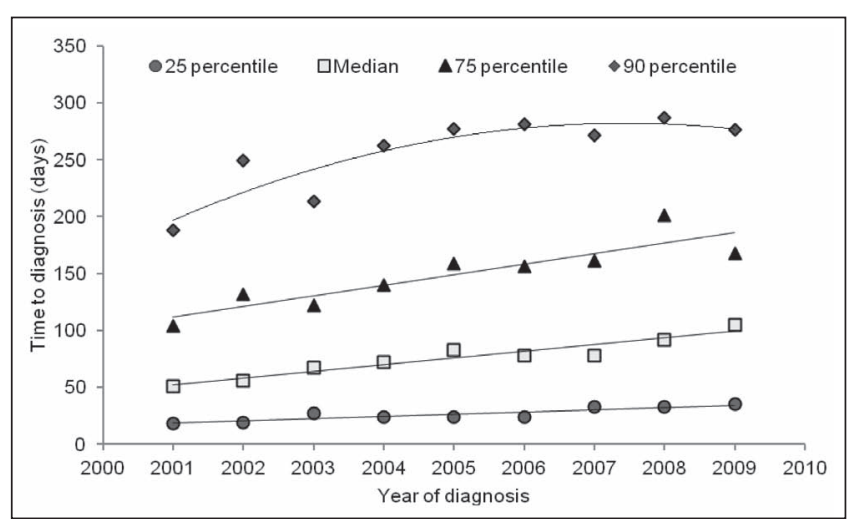

Figure 1) Time to diagnosis according to year of diagnosis. The figure includes the time to colorectal cancer diagnosis in the urban areas for 2001 to 2003 from a previous study (4)

Individuals with CRC diagnosed between January 1, 2004 and March 31, 2009 were followed up to migration from the province, death or March 31, 2010, whichever occurred first. Multivariate logistic regression analysis was performed to determine the association between time to diagnosis and the tumour stage at diagnosis. Potential confounding factors considered included age, sex, socioeconomic status (SES), comorbidity index score (Charlson comorbidity index score [10,11], based on all diagnoses during the hospitalizations in the year before CRC diagnosis), the calendar year of colon cancer diagnosis, stage at diagnosis (for survival analysis), tumour grade, site of CRC (colon versus rectum [rectosigmoid were included with rectum]), admission through an emergency room in the month before diagnosis and the type of first gastrointestinal test. SES was assigned to study subjects based on their neighbourhood of residence on the date of CRC diagnosis using the Socioeconomic Factor Index, a previously validated measure $(12-14)$. Potential confounders were retained in the multivariate models if they resulted in a $10 \%$ or higher change in the crude HRs or ORs. Although individuals with FOBT as their first test were excluded from the presented regression analysis, sensitivity analyses including such individuals had no appreciable effect on the estimates. FOBT is usually performed for CRC screening and is the recommended test for CRC screening by the Manitoba's CRC screening program. The time to diagnosis was evaluated as a continuous variable and, in alternative models, categorized into quartiles and longest ( $>90$ th percentile) time to diagnosis versus the rest.

\section{RESULTS}

A total of 2310 CRC cases were included in the study (median age 72 years [interquartile range 60 to 80 years]); $53 \%$ of cases were men). A summary of the cases is provided in Table 1 . The median time to

\section{TABLE 3}

Multivariate logistic regression analysis of risk of laterstage colorectal cancer at diagnosis (III/IV versus I/II) in relation to time to diagnosis

\begin{tabular}{lc}
\hline Time to diagnosis (days) & Adjusted OR* $(95 \% \mathrm{Cl})$ \\
\hline For each increase of 30 days & $0.94(0.89-0.98)$ \\
Quartile $1(<15)$ & 1.00 (Reference) \\
Quartile $2(15$ to $<51)$ & $0.79(0.52-1.20)$ \\
Quartile $3(51$ to $<116)$ & $0.59(0.39-0.89)$ \\
Quartile $4(\geq 116)$ & $0.50(0.33-0.75)$ \\
$\leq 90$ percentile $(<239)$ & 1.00 (Reference) \\
$>90$ percentile $(\geq 239)$ & $0.84(0.53-1.33)$ \\
\hline
\end{tabular}

*Individuals with fecal occult blood test as their first test were excluded from the presented regression analysis. Sensitivity analyses including such individuals had no appreciable effect on the estimates

diagnosis over all of the study years was 81 days, and increased from 72 days in 2004 to 105 in 2009 ( $\mathrm{P}=0.04$ ) (Table 2, Figure 1). There was no significant increase in time to treatment. The estimated time to diagnosis was $>161$ days for $25 \%$ of cases and $>277$ days for $10 \%$ of cases. The time between index contact and first colonoscopy increased from 72 days in 2004 to 111 days in $2009(\mathrm{P}=0.02)$.

Fifty per cent of the cases had stage III or IV disease at diagnosis. This association persisted irrespective of whether the time to diagnosis was evaluated as a continuous variable or categorized into quartiles (Table 3). This association persisted irrespective of whether the time to diagnosis as a continuous variable or categorized into quartiles was evaluated. Those who waited $>90$ th percentile of time to diagnosis had a nonsignificant lower OR for stage III or IV disease.

Forty one per cent of cases diagnosed over the study period died before the end of follow-up in 2010. There was no statistically significant association between the time to diagnosis and hazard for death after CRC diagnosis (Table 4). Those who waited the longest ( $>90$ th percentile of time to diagnosis) had a $40 \%$ nominally nonsignificant increased hazard for death after CRC diagnosis (HR 1.40 [95\% Cl 1.00 to 1.96 ]; $\mathrm{P}=0.05$ ). There was no significant interaction between stage of CRC at diagnosis and time to diagnosis in any of the models for hazards for death after CRC diagnosis.

\section{DISCUSSION}

Results of the present study suggest that although the time to diagnosis for CRC increased between 2004 and 2009 in urban areas of Manitoba, the longer time to diagnosis did not have an adverse effect on clinical outcomes, such as stage at diagnosis or survival after CRC diagnosis.

While it seems logical to expect that a very long time to diagnosis would adversely affect patient outcomes, CRC is a slow-growing disease and, hence, the usual times to diagnosis in clinical practice may 


\begin{tabular}{|c|c|}
\hline Time to diagnosis (days) & Adjusted HR* $(95 \% \mathrm{Cl})$ \\
\hline For each increase of 30 days & $1.01(0.98-1.05)$ \\
\hline Quartile 1 (<15) & 1.00 (Reference) \\
\hline Quartile $2(15$ to <51) & $1.03(0.78-1.37)$ \\
\hline Quartile $3(51$ to $<116)$ & $0.99(0.72-1.35)$ \\
\hline Quartile 4 ( $\geq 116)$ & $1.07(0.79-1.44)$ \\
\hline$\leq 90$ percentile $(<239)$ & 1.00 (Reference) \\
\hline$>90$ percentile $(\geq 239)$ & $1.40(1.00-1.96)$ \\
\hline
\end{tabular}

*Individuals with fecal occult blood test as their first test were excluded from the presented regression analysis. Sensitivity analyses including such individuals had no appreciable effect on the estimates

not have significant adverse effects on patient outcomes - as suggested by our study. Data from other countries on the association of diagnostic delays for CRC and patient outcomes are conflicting $(15,16)$. However, the previous studies did not evaluate the effect of extreme delays (eg, $>90$ th percentiles of time to diagnosis) on patient outcomes and were performed in countries with different models of health care delivery than Canada. Physicians appear to be able to clinically recognize many of the sicker patients with more advanced disease and, hence, speed up their evaluation - as suggested by the association between shorter time to diagnosis and advanced tumour stage at diagnosis in our study. However, the capacity of the health care system to respond to the physicians' efforts in this regard likely varies in different jurisdictions. Therefore, it is important to assess the effect of time to diagnosis on patient outcomes in different health care systems. Our results should be reassuring to health care providers and patients in Manitoba, and probably in Canada, that wait times for CRC diagnosis in usual practice have, so far, largely not adversely affected major clinical outcomes.

On the other hand, our results should not discourage efforts to decrease diagnostic wait times in Canada. Individuals awaiting evaluation for possible diagnosis of cancer experience an increased anxiety level, which may be reduced only by more prompt evaluations. Statistical significance should not be the only arbiter of an appropriate wait time. Recently, the Organisation for Economic Co-operation and Development (OECD) reported that overall, the wait times for health care were the longest in Canada, even though Canada spent a higher proportion of gross domestic product on health care than the average in OECD countries (17). In this regard, our finding of a continuing increase in time to diagnosis for CRC over almost a decade (Figure 1) is concerning. There was also a signal in our study that extreme times to diagnosis for CRC, as are beginning to occur, will start affecting clinical outcomes. We found that those with a wait time that was $>90$ th percentile time to diagnosis had an increased hazard of death after CRC diagnosis that just failed to reach statistical significance. Additional studies should evaluate the threshold when the wait times to diagnosis become clinically significant.

The increase in time to diagnosis found in our study was likely at least partially due to increased screening for CRC, including screening colonoscopy performed opportunistically. Increased screening activity with no concomitant organized increase in endoscopy resources and/or reorganization of endoscopy services leads to increased demand on endoscopy services and could result in increased wait times for diagnosis.

Our results should be interpreted in the context of the present study's strengths and limitations. Manitoba has relatively robust databases, which were used in the study. Cancer stage is the most important prognostic factor for survival after cancer diagnosis and needs to be accounted for in any evaluation of the patient outcomes. Manitoba was one of the first provinces to routinely record stage at diagnosis for CRC and, hence, we were in a unique position to perform the study. We did not rely on patient recall and, therefore, avoided the risk of recall bias, which is inherent in studies relying on patient surveys after cancer diagnosis. However, the present analysis was a historical cohort study and we did not specifically validate the estimated times. Prospective databases need to be established to study the different components of wait times, but are currently lacking other than for time to treatment after diagnosis; electronic health records, when more widely used, should make it easier to collect such data.

\section{CONCLUSION}

Time to diagnosis for CRC increased between 2004 and 2009 in the urban areas in Manitoba. However, the present study did not detect a negative effect of increasing time to diagnosis on clinical outcomes. Additional studies should evaluate the threshold at which prolonged time to diagnosis starts influencing clinical outcomes in usual care in Canada.

DISCLOSURES: The authors have no financial disclosures or conflicts of interest to declare. The results and conclusions are those of the authors, and no official endorsement by Manitoba Health is intended or should be inferred. Dr Singh is supported in part by an ACG Junior Faculty Development Grant. Dr Bernstein holds the Bingham Chair in Gastroenterology. All of the authors were involved in the study concept and design; acquisition of data; analysis and interpretation of data; and critical revision of the manuscript for important intellectual content.

\section{REFERENCES}

1. Manitoba Health. Working for better health care sooner. Report to Manitobans on health care services. <www gov mb ca/health/ waittime/report2006 pdf> 2006 May (Accessed October 5, 2012).

2. Ontario Ministry of Health and Long-Term Care. Wait times targets. $<$ www health gov on ca/transformation/wait_times/providers/wt_ target html> 2008 October 17 (Accessed October 15, 2011).

3. Canadian Cancer Society/National Cancer Institute of Canada. Canadian Cancer Statistics 2008. Toronto, 2008.

4. Singh H, De CC, Shu E, et al. Wait times from presentation to treatment for colorectal cancer: A population-based study. Can J Gastroenterol 2010;24:2433-9.

5. Wilkins K, Shields M. Colorectal cancer testing in Canada - 2008. Health Rep 2009;20:21-30.

6. Hotes Ellison J, Wu XC, McLaughlin C, et al eds. Cancer in North America: 1999-2003, vol 1. Incidence. North American Asociation of Central Cancer Registeries Inc: 2006:II-325.

7. Robinson JR, Young TK, Roos LL, Gelskey DE. Estimating the burden of disease. Comparing administrative data and self-reports. Med Care 1997;35:932-47.

8. Roos LL, Mustard CA, Nicol JP, et al. Registries and administrative data: Organization and accuracy. Med Care 1993;31:201-12.

9. Roos LL Jr, Nicol JP, Cageorge SM. Using administrative data for longitudinal research: Comparisons with primary data collection. J Chronic Dis 1987;40:41-9.

10. Quan H, Sundararajan V, Halfon P, et al. Coding algorithms for defining comorbidities in ICD-9-CM and ICD-10 administrative data. Med Care 2005;43:1130-9.

11. Sundararajan V, Quan H, Halfon P, et al. Cross-national comparative performance of three versions of the ICD-10 Charlson index. Med Care 2007;45:1210-5.

12. Martens PJ, Frohlich N, Carriere KC, Derksen S, Brownell M. Embedding child health within a framework of regional health: Population health status and sociodemographic indicators. Can J Public Health 2002;93(Suppl 2):S15-S20.

13. Martens PJ, Derksen S, Gupta S. Predictors of hospital readmission of Manitoba newborns within six weeks postbirth discharge: A population-based study. Pediatrics 2004;114:708-13.

14. Frohlich N, Mustard C. A regional comparison of socioeconomic and health indices in a Canadian province. Soc Sci Med 1996;42:1273-81

15. Ramos M, Esteva M, Cabeza E, Llobera J, Ruiz A. Lack of association between diagnostic and therapeutic delay and stage of colorectal cancer. Eur J Cancer 2008;44:510-21.

16. Ramos M, Esteva M, Cabeza E, Campillo C, Llobera J, Aguila A. Relationship of diagnostic and therapeutic delay with survival in colorectal cancer: A review. Eur J Cancer 2007;43:2467-78.

17. OECD. Health at a Glance 2011: OECD Indicators. $<$ http://dx doi org/10 1787/health_glance-2011-en> 2011 (Accessed October 5, 2012). 


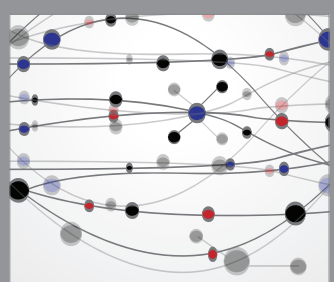

The Scientific World Journal
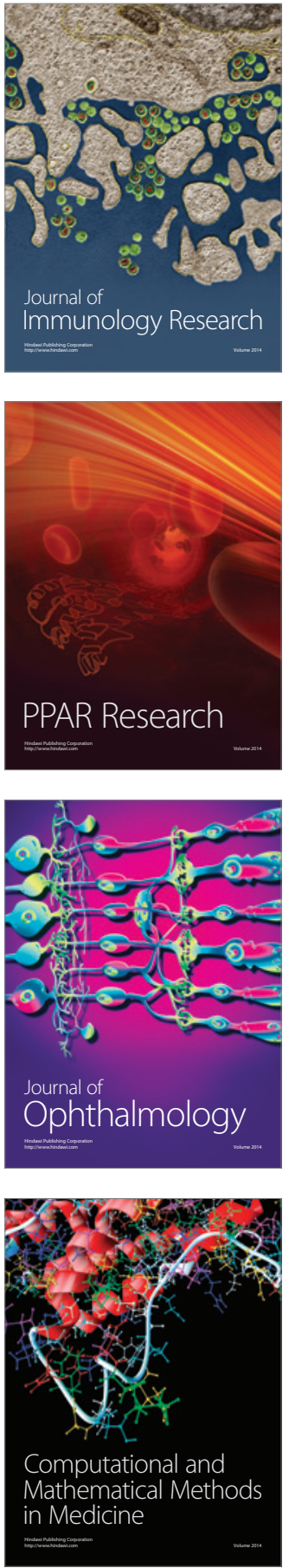

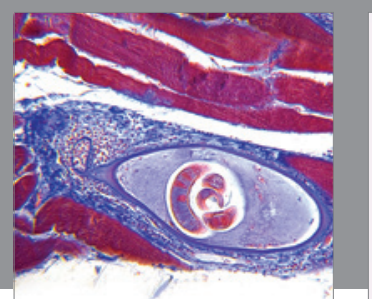

Gastroenterology Research and Practice

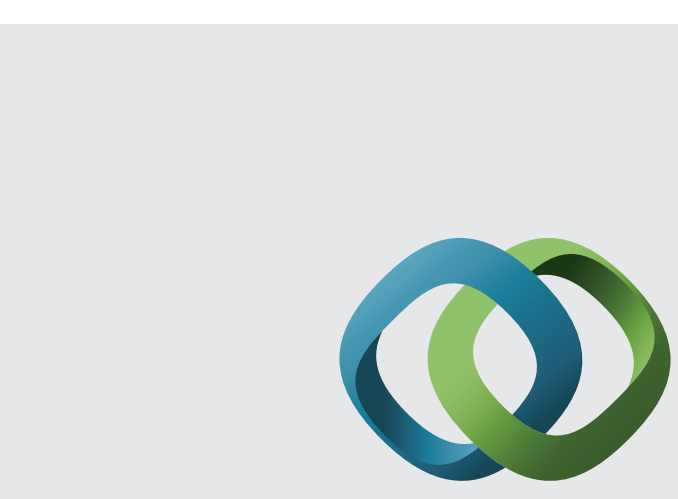

\section{Hindawi}

Submit your manuscripts at

http://www.hindawi.com
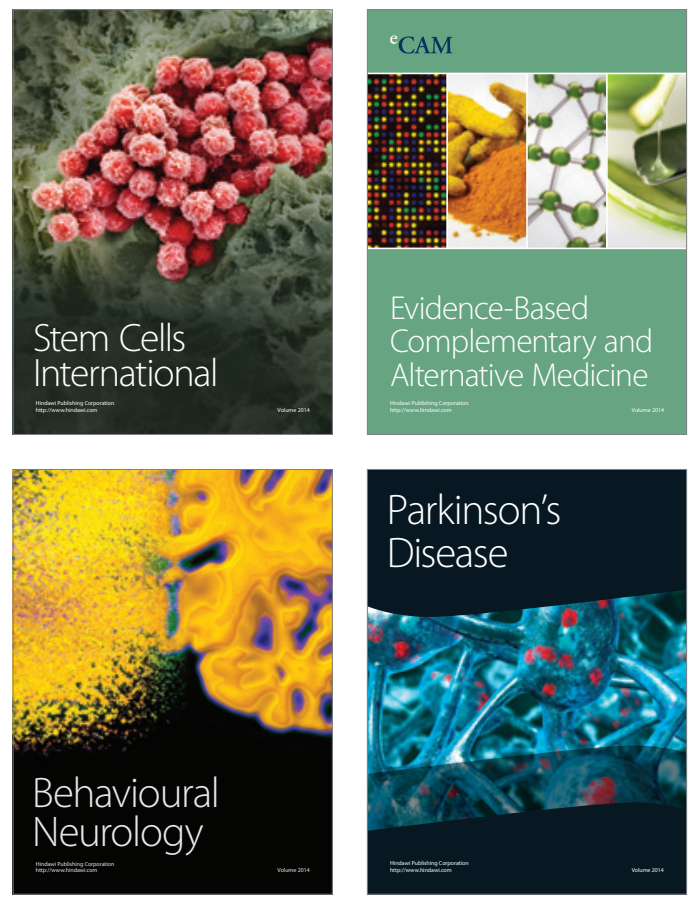
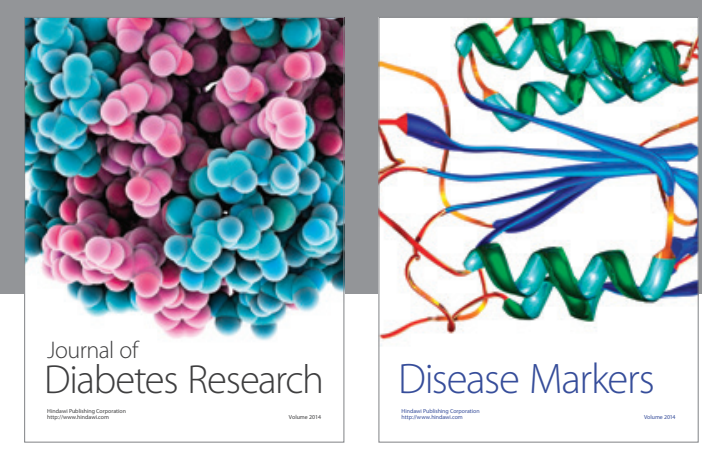

Disease Markers
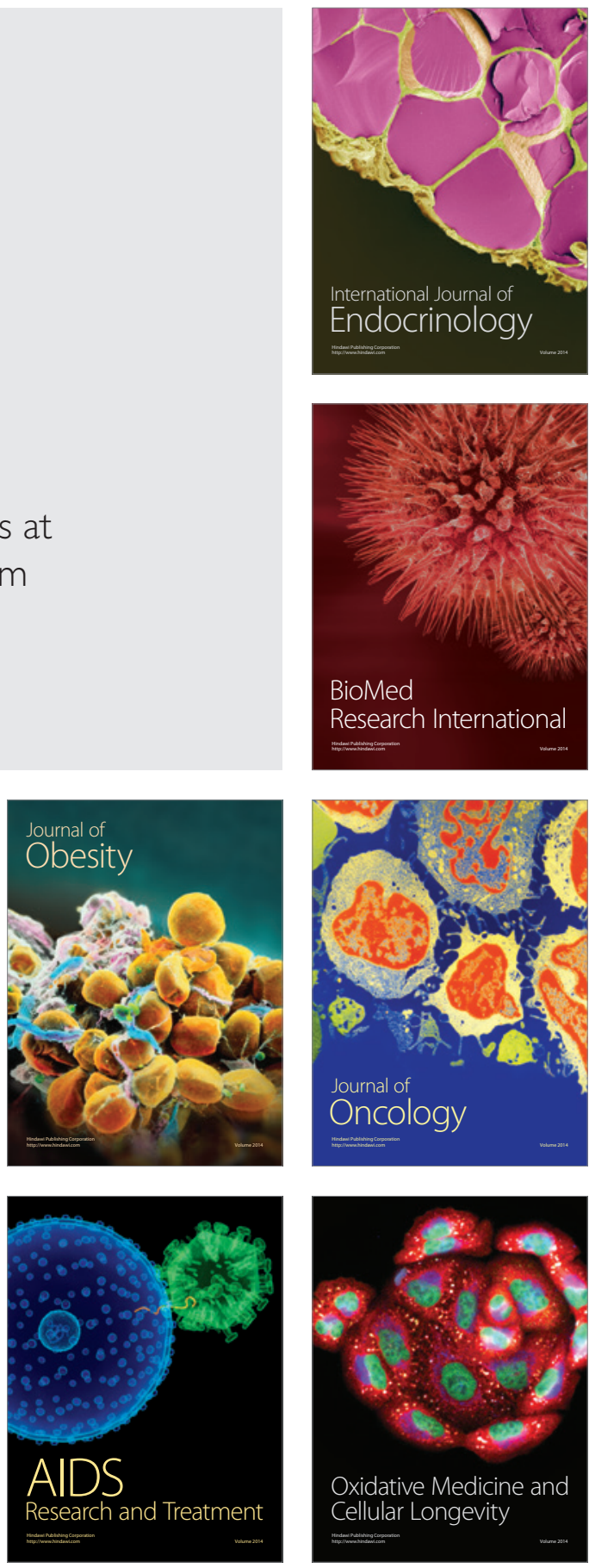